\title{
A dynamic credit ratings model
}

\author{
D.E. Allen ${ }^{\text {a }}, \underline{\text { R.J. Powell }}^{\text {a }}$ and A.K. Singh ${ }^{a}$ \\ ${ }^{a}$ Edith Cowan University, Western Australia \\ Email: r.powell@ecu.edu.au
}

\begin{abstract}
The Global Financial Crisis (GFC) provided overwhelming evidence of the problems caused by inadequate credit ratings. Losses and problem loans experienced by banks over this period were staggering. Yet many of the securitized sub-prime parcels which were widely seen as an underlying cause of the GFC, as well as corporate obligors who experienced severe difficulties during the GFC, retained extremely strong external credit ratings. They may have had low perceived risk at the time of rating, but as circumstances changed, the ratings stayed static and became far removed from the underlying risk. A key problem is that the external credit ratings do not fluctuate with changing economic circumstances. Whilst there are models which measure changing default risk, they are not linked to credit ratings and it is often the rating itself, not the underlying risk that drives behavior, such as the purchase of securitized parcels, the pricing of credit risk, and the allocation of capital for credit risk, which under the Basel standardized model for corporates is based on the rating itself. This problem is exacerbated by the fact that these ratings carry descriptors such as "extremely strong capacity". This descriptor may no longer be appropriate for the rated company if the market turns dramatically, yet the rating and descriptor remain unchanged.
\end{abstract}

To overcome this problem, this paper shows how an innovative fluctuating credit ratings model can be generated by linking the Merton structural credit model to a credit ratings framework. The Merton model measures fluctuations in daily asset values and, using a combination of these fluctuating asset values and the capital structure of a company, it measures Distance to Default (DD) and the Probability of Default (PD) associated with each DD. Under the Merton structural model, default occurs when the firm's debt exceeds asset values. Thus as fluctuations in asset values become more volatile, DD also becomes more volatile and PD increases. External raters such as Moody's provide PD's associated with each rating. Thus by using the Merton model, we are able to generate PDs which fluctuate over time and link these PD's to credit ratings. Therefore, as our PD's fluctuate, so do the credit ratings.

To illustrate our approach, we apply this model to a French motor vehicle company (Renault) which experienced severe distress during the GFC. We compare the Moody's rating changes that took place for Renault over the 2006 - 2009 period, which captures the events leading up to and during the GFC. Over this period, only three Moody's external ratings changes took place and throughout this period, Renault stayed in the Moody's 'moderate' risk band. Based on this, an investor would likely assume the company was in reasonable financial health, and a bank would not be required to change its capital allocation for this company if it was a borrower. Yet during this period, the company experienced such severe financial problems that it had to be bailed out by the French Government. Our model, on the other hand, recognizes these stresses far quicker, starting with rating downgrades for Renault from August 2007 and moving downwards through several risk bands, from 'moderate' to 'substantial' to 'high' and then to 'very high' credit risk. This downward spiral is far more in keeping with the actual problems experienced by Renault than the static 'moderate' risk tag would indicate. We thus find that the new model responds extremely rapidly to changing economic circumstances to produce ratings which can far more accurately depict the underlying credit risk of a corporate obligor in these times than prevailing external rating methods.

The new ratings can benefit bond investors and banks through improved knowledge of the underlying credit risk of bonds and of corporate borrowers. As capital adequacy can also be linked to credit ratings, an improved rating model can assist banks and regulators to better measure required capital adequacy to protect against economic downturns.

Keywords: $\quad$ Credit risk, Credit ratings, Fluctuating default risk 


\section{INTRODUCTION}

During the GFC external credit rating agencies were severely criticized for having provided credit ratings which did not reflect the inherent risk of the underlying asset or entity. Over the two years to 2009, impaired assets (problem loans) in the US trebled from $2.4 \%$ of total assets to $8.8 \%$, an increase of USD 480 billion. UK bank impaired assets increased from $2.1 \%$ to $6.6 \%$ over this period, an increase of USD 576 billion. The 5 largest US banks lost nearly USD 50 billion in 2008, and the 5 largest banks in the UK lost approximately $£ 20$ billion (Reserve Bank of Australia, 2009a). More than 400 US banks failed in 2009 compared to 25 in 2008, 3 in 2007 and none in the prior two years. Australian banks, although faring better with no bank failures, nonetheless had a fivefold escalation in impaired assets (although off a smaller base than the US and UK) from $0.2 \%$ to $1.0 \%$ (Reserve Bank of Australia, 2009b). Globally, governments had to provide hundreds of billions of dollars to support banks. Examples include the 2008 US \$700bn Troubled Asset Relief (TARP) Programme and the 2008 UK $£ 500 \mathrm{bn}$ financial support package. Many countries, including Australia, had to introduce (or increase) government deposit guarantees to shore up confidence in banks.

Yet the enormity of these problems was never reflected in credit ratings!

Indeed, many securitized sub-prime parcels, which are widely seen as an underlying cause of the GFC (see for example Keys, Mukherjee, Seru, \& Vig, 2010) were rated AAA. They may have had low perceived risk at the time of rating, based on historically low bad debt experience of home loans, but as circumstances changed (falling house prices and increasing interest rates), the ratings stayed static and became far removed from the underlying risk. Many banks that were struggling retained static ratings right throughout most or all of the GFC. As the problems spread to the corporate obligors, and bank bad debts escalated enormously, credit ratings for these obligors generally stayed static until long after the problems had passed. The problem is that credit ratings are undertaken only periodically (often annually or even with several years in between ratings) and do not reflect changes in circumstances in the intervening period. According to Moody's (2013b) "our ratings are not intended to ratchet up and down" with changing economic conditions, rather ratings are designed to be measures of relative risk. While this may be fine when comparing the relative risk of one loan or bond to another, it becomes a problem when using ratings for purposes such as: a bank allocating capital under the Basel II (and Basel III) standardised credit risk model (Bank for International Settlements, 2004, 2011), which is based on external ratings; or to provide a loan to a rated customer; or to allocate lending approval limits to loan officers based on ratings; or for an investor to understand the risk of a bond based on static ratings in dynamic circumstances. All of these require an appropriate current rating, rather than a relative rating set some time back. The descriptor allocated to a rating, such as "moderate risk" may no longer be appropriate for the company if the market turns dramatically, yet the rating and descriptor remain unchanged. The example in the following table shows the probability of default (PD) that Moody's (2010) allocated to rankings Baa1 and Ba3 across the height of the GFC.

Table 1. Moody's PD rankings associated with selected ratings (\%)

\begin{tabular}{lcc} 
& Ba3 PD & Caa2 PD \\
\cline { 2 - 3 } 2006 & $0.484 \%$ & $6.742 \%$ \\
2007 & $0.000 \%$ & $8.222 \%$ \\
2008 & $2.715 \%$ & $18.812 \%$ \\
2009 & $4.010 \%$ & $39.298 \%$
\end{tabular}

Table 1 shows that an obligor could have a massive PD increase from 2006 - 2009, yet retain the same ranking, descriptor, and capital allocation. The above discussion shows the highly significant problems that can occur due to inappropriate ratings, including poor investment and loan decisions, inadequate bank capital, and severe bank stresses which all have major implications for financial stability. Thus there is a strong need to revisit current static credit rating methods. Research which leads to credit ratings systems that more accurately measure ratings, respond quickly to dynamic economic circumstances and improve capital adequacy decisions for banks, would make a highly significant contribution to the field of credit risk measurement. That is exactly the purpose of this paper. The aim of the study is to develop credit ratings which accurately reflect prevailing circumstances and which respond rapidly as these circumstances change. The dynamic credit ratings framework proposed in this research is an entirely original and innovative concept which could potentially change the face of future credit rating systems, leading to significant improvements in the understanding and measurement of credit risk. 
To illustrate our methodology, we use the example of Renault, a French motor vehicle company which experienced severe stress during the GFC and required French Government bailout. It should be noted that this study is by no means intended as a comprehensive analysis, but rather as an exploratory paper which outlines a potential framework for generating dynamic ratings, and which is to be further explored and developed in future studies which can test the robustness of this proposed ratings framework in a wide range of markets and scenarios. Section 2 of this paper discusses our methodology. To put our example in context, Section 3 provides a brief background on Renault and the circumstances under which the motor vehicle industry was operating over the GFC. Section 4 presents and discusses results and Section 5 concludes.

\section{METHODOLOGY}

The previous section discussed the highly static or 'sluggish' nature of credit ratings and how they do not 'ratchet' up or down with changing economic circumstances, which is a key disadvantage of current rating models. At the time of the rating taking place, there is a thorough and detailed assessment of the risk of the firm by the external rater (including factors such as financial accounts, the industry and the firm management). The problem is that this assessment may no longer be valid as circumstances change. This research intends to link market based measurements of asset quality to credit ratings to produce 'ratcheting ratings' which do fluctuate in tandem with economic circumstances.

We use the Merton (1974) structural model as modified by Moody's KMV (Crosbie \& Bohn, 2003) hereafter referred to as the Merton/KMV model. Merton/KMV holds that the determinants of default are: asset values of a firm, fluctuations in those asset values, and the leverage. These items are used to calculate Distance to Default (DD) and Probability of Default (PD). The firm defaults when debt exceeds market asset values. A significant advantage that this model has over other credit models is that it responds rapidly to changing market conditions, as share price values are a core component of fluctuating asset values. These fluctuating asset values can be measured frequently, even daily, whereas models based on credit ratings are much slower to respond. The Merton/KMV model has been shown to have a much higher accuracy than these other models in times of economic distress, as shown for example in Allen and Powell (2010). Nobel laureate Robert Engel (2011) finds that there is a strong link between falling equity prices and bankruptcy and uses a Merton style model to effectively measure systemic risk. Auvray \& Brossard (2012) find that the model can be a good lead indicator of bank distress, due to its market component. We link the asset fluctuations generated by Merton KMV to credit ratings, thus creating an original, innovative and dynamic ratcheting rating system, allowing the rating to fluctuate with market conditions.

Volatility in market value of assets, is measured by Merton/KMV as the standard deviation of asset returns $\left(\sigma_{V}\right)$. We use the approaches outlined by KMV (Crosbie \& Bohn, 2003) and Bharath \& Shumway (2008). Initial asset returns (for every day) in our data set are estimated from historical daily equity data using the following formula, where $E$ is the market capitalization of the firm:

$$
\sigma_{V}=\sigma_{E}\left(\frac{E}{E+F}\right)
$$

$\mathrm{DD}$ is measured in line with usual practice for Merton/KMV:

$$
D D=\frac{\ln (V / F)+\left(\mu-0.5 \sigma_{V}^{2}\right) T}{\sigma_{V} \sqrt{T}}
$$

Where $\mathrm{V}$ is the market value of the firm, $\mathrm{F}=$ face value of firm's debt, and $\mu=$ an estimate of the annual return (drift) of the firm's assets. T is the selected forecasting time period. In line with KMV, debt is taken as the value of all short-term liabilities (one year and under) plus half the book value of all long term debt outstanding. DD as measured above is the number of standard deviations away from default.

Probability of Default (PD) can be determined using the normal distribution. For example, if DD $=2$ standard deviations, we know there is a 95\% probability that assets will vary between 1 and two standard deviations. There is a $2.5 \%$ probability that they will fall by more than 2 standard deviations. Using $\mathrm{N}$ as the cumulative standard normal distribution function, PD is measured as:

$$
P D=N(-D D)
$$

There are two problems with this PD calculation. First it assumes that PD's follow a normal distribution. This is often not the case with credit risk which can be characterized with high losses in the tail of the distribution, especially in turbulent times such as was seen over the GFC. Secondly Moody's KMV have an extensive database of actual losses, and find that the PD's yielded by equation 3 are often much too small. To 
overcome these problems, KMV calibrate the DD's to actual experienced losses, to provide an Estimated Default Frequency (EDF). They also provide a cap and a floor on their EDF's which range between $0.1 \%$ and $35 \%$ as compared to equation 3 , which can range between $0 \%$ and $50 \%$. The EDFS also tend to be higher than the PDF when DD is high, for example, when DD is 4, then PD is $0.0003 \%$, but EDF is $0.4 \%$. Moody's (2012) provide a graph of how the EDF maps to PD. Whilst we use the PD calculation in our analysis, we also explain how this differs from EDF.

As we are using daily asset returns, we can estimate the DD per equation 2 at any point (day month or year) in the cycle. We have calculated DD on a monthly basis to show how it fluctuates. We then then calculate the PD associated with each DD per equation 3. Rather than allowing the PDs to shift around like Moody's and S\&P, we maintain a constant band of PD's for each rating (based on Moody's PD values at our starting point in 2006), and then change the rating if it falls above or below that threshold.

\section{BACKGROUND TO OUR EXAMPLE: THE COMPANY AND THE INDUSTRY}

Renault is a French motor vehicle manufacturer established in 1899. It is Europe's fifth largest motor vehicle manufacturer (behind Volkswagen, Daimler, BMW and Fiat and ahead of Peugeot/Citroen per figures obtained from Datastream) with sales of $€ 43 \mathrm{bn}$ in 2012 and total assets of $€ 43 \mathrm{bn}$.

Globally, the new car market suffered severe problems during the GFC with General Motors and Chrysler filing for bankruptcy in 2008, and many other manufacturers, including one of the world's largest car manufacturers Toyota, posting losses in 2009. This led to many manufacturers downsizing their operations. In Europe, Volkswagen and BMW experienced significant profit reductions in 2009, with Daimler, Fiat, Renault and Peugeot all experiencing losses. Along with global trends, share prices in the European car market plunged $70 \%$ from its peak in 2007 to its trough in 2008. Globally, including Europe, the motor vehicle industry was beset by downsizing, job losses and restructuring. There are some key reasons why the new motor vehicle industry is particularly susceptible to economic downturns. Job losses cause reductions in discretionary purchases. Even employed consumers often put larger purchases such as vehicles on hold during difficult economic times. Sales are also highly reliant on motor vehicle finance being provided to purchasers. This latter issue was particularly prevalent during the GFC when the credit crunch following the sub-prime problems made it very difficult to obtain motor vehicle finance. When automakers started experiencing major problems, they then it found it almost impossible to raise further finance to keep their companies afloat.

In 2008 , Renault experienced a $78 \%$ profit drop and in 2009 , suffered losses of $€ 3$ bn. Faced with difficulties in obtaining finance and the prospect of huge job losses and plant closures, Renault and Peugeot Citroen each received French Government bailout packages of $€ 3$ bn. For several years prior to the GFC, Renault had enjoyed good profitability and stability and was rated A2 by Moody's. The company was downgraded to Baa1 in December 2006, to Baa2 in September 2008 and to Baa3 in August 2009. These ratings will be further discussed in Section 4.

\section{RESULTS AND DISCUSSION}

The results of our analysis of Renault are presented in Table 2. Column 1 shows that Moody's re-ratings occurred only three times across the sample period, moving from Baa1 to Baa2 to Baa3. Column 2 shows the PDs associated with the Moody's ratings as per Moody's (2010), remembering that our example is using the PDs for each rating band as reported by Moody's at our start date of 2006 as we do not allow the PDs associated with each band to fluctuate, rather allowing the ratings to fluctuate. Column 3 shows the DD calculated for each month using equation 1. The DD reduces quite dramatically over the period from a high of 7.59 in June 2007 to a low of 1.98 in February 2009. Allen, Kramadibrata, Powell \& Singh (2013) show that during the GFC, Peugeot had the lowest DD of all the European motor vehicle manufacturers. DD per equation 1 and equation 2, essentially comprises two key elements, being equity (assets less debt) and fluctuations in the market asset values. At the height of the GFC, Renault had equity of 53\%, broadly in line with the average for the motor vehicle manufacturing industry in Europe, so Renault's DD problems related more to the fluctuations in market value of assets (as opposed to equity), brought about by the problems they were experiencing as summarized in Section 3. Column 4 shows the implied PD associated with each monthly DD, calculated using equation 3. This climbs from $0.00 \%$ to a peak of $2.41 \%$, as opposed to the static $0.00 \%$ that is indicated by the Moody's rating. Column 5 then applies the Moody's rating that is associated with each PD. For example, in 2006 Moody's PD associated with B1 was $0.78 \%$. As PD exceeds that threshold in Sept 2008, Column 5 applies a B1 rating for Sept 2008. Moody's PD for Caal in 2006 was 
2.279 and the PD in Column 5 exceeds that threshold in February 2009, a Caa1 rating is applied in that month.

It can be seen in the last two columns that our dynamic ratings change far sooner (and fall much further) than the external ratings, as our ratings respond immediately to the fluctuating market asset values captured by DD, in line with the problems experienced by Renault.

We have mentioned that KMV EDF values are higher than PD values and also have a floor of $0.1 \%$, which means our rating changes based on PD are conservative. An EDF distribution provided by Moody's indicates that the ratings for Renault based on EDF would be approximately 1 rating lower than we have provided here, e.g. $\mathrm{Ba} 3$ where our PD indicates $\mathrm{Ba} 2$, but would not fall further than Caa1, which is the same riskiest point as indicated by our PD.

Table 2. Comparing actual ratings to our dynamic ratings

\begin{tabular}{|c|c|c|c|c|c|c|}
\hline & Date & $\begin{array}{r}\text { Column } 1 \\
\text { Moody's } \\
\text { Rating } \\
\end{array}$ & $\begin{array}{r}\text { Column } 2 \\
\text { Moody's } \\
\text { PD (\%) } \\
\end{array}$ & $\begin{array}{r}\text { Column } 3 \\
\text { Our } \\
\text { DD } \\
\end{array}$ & $\begin{array}{r}\text { Column } 4 \\
\text { Our } \\
\text { Implied PD (\%) } \\
\end{array}$ & $\begin{array}{r}\text { Column } 5 \\
\text { Our Dynamic Rating } \\
\text { (Moody's Numbering) } \\
\end{array}$ \\
\hline 2009 & August & Baa3 & $0.00 \%$ & 2.23 & $1.29 \%$ & $\mathrm{~B} 2$ \\
\hline & July & & & 2.21 & $1.35 \%$ & B2 \\
\hline & June & & & 2.17 & $1.50 \%$ & B2 \\
\hline & May & & & 2.18 & $1.46 \%$ & B2 \\
\hline & April & & & 2.15 & $1.57 \%$ & B2 \\
\hline & March & & & 2.03 & $2.09 \%$ & B2 \\
\hline & February & & & 1.98 & $2.41 \%$ & Caa1 \\
\hline & January & & & 2.03 & $2.12 \%$ & B2 \\
\hline 2008 & December & & & 2.08 & $1.89 \%$ & B2 \\
\hline & November & & & 2.06 & $1.96 \%$ & B2 \\
\hline & October & & & 2.14 & $1.61 \%$ & B2 \\
\hline & September & Baa2 & $0.00 \%$ & 2.37 & $0.89 \%$ & B1 \\
\hline & August & & & 3.18 & $0.07 \%$ & $\mathrm{Ba} 2$ \\
\hline & July & & & 3.14 & $0.08 \%$ & $\mathrm{Ba} 2$ \\
\hline & June & & & 3.13 & $0.09 \%$ & $\mathrm{Ba} 2$ \\
\hline & May & & & 3.27 & $0.05 \%$ & $\mathrm{Ba} 2$ \\
\hline & April & & & 3.27 & $0.05 \%$ & $\mathrm{Ba} 2$ \\
\hline & March & & & 3.31 & $0.05 \%$ & $\mathrm{Ba} 2$ \\
\hline & February & & & 3.33 & $0.04 \%$ & $\mathrm{Ba} 2$ \\
\hline & January & & & 3.37 & $0.04 \%$ & $\mathrm{Ba} 2$ \\
\hline 2007 & December & & & 3.58 & $0.02 \%$ & $\mathrm{Ba} 2$ \\
\hline & November & & & 3.62 & $0.01 \%$ & $\mathrm{Ba} 2$ \\
\hline & October & & & 3.78 & $0.01 \%$ & $\mathrm{Ba} 2$ \\
\hline & September & & & 7.41 & $0.00 \%$ & Baal \\
\hline & August & & & 7.38 & $0.00 \%$ & Baal \\
\hline & July & & & 7.47 & $0.00 \%$ & Baal \\
\hline & June & & & 7.59 & $0.00 \%$ & Baa1 \\
\hline & May & & & 7.46 & $0.00 \%$ & Baa1 \\
\hline & April & & & 7.35 & $0.00 \%$ & Baal \\
\hline & March & & & 7.26 & $0.00 \%$ & Baa1 \\
\hline & February & & & 7.30 & $0.00 \%$ & Baal \\
\hline & January & & & 7.36 & $0.00 \%$ & Baa1 \\
\hline 2006 & December & Baal & $0.00 \%$ & 7.30 & $0.00 \%$ & Baal \\
\hline
\end{tabular}

Table 2 shows that Moody's ratings stayed at the Baa level throughout the period. Moody's (2013a) description for a Baa rating is, among other wording, "moderate credit risk". The numerical modifiers 1, 2 and 3 do not change the description but a modifier of 1 indicates that it is at the higher end of the generic rating category, a modifier of 2 at the mid-rage, and a modifier of 3 at the lower end. Table 3 shows that the credit risk description stays the same throughout the period based on Moody's ratings. Based on our dynamic ratings, it moves through a range of descriptions from moderate though substantial, through high, to very high. Given that Renault moved from a stable profitable company in the early 2000's to one that required government bailout in 2009, it is not feasible that the credit risk descriptor should stay the same. Our model captures these events. From an EDF perspective, the range of rating descriptors would not differ substantially from those of our PD indicators below: as discussed above Table 3, they would be approximately 1 rating lower than those indicated by DD, which in most months for Renault will only affect the numerical modifier rather than the rating band and description. 
Table 3. Rating Descriptions.

\begin{tabular}{lll} 
& Moody's Descriptor & Moody's Descriptor \\
Date & Based on Moody's rating & Based on Our Implied PD \\
\hline August & Moderate credit risk & High credit risk \\
July & Moderate credit risk & High credit risk \\
May & Moderate credit risk & High credit risk \\
April & Moderate credit risk & High credit risk \\
March & Moderate credit risk & High credit risk \\
February & Moderate credit risk & High credit risk \\
January & Moderate credit risk & Very high credit risk \\
2008 December & Moderate credit risk & High credit risk \\
November & Moderate credit risk & High credit risk \\
October & Moderate credit risk & High credit risk \\
September & Moderate credit risk & High credit risk \\
August & Moderate credit risk & High credit risk \\
July & Moderate credit risk & Substantial credit risk \\
June & Moderate credit risk & Substantial credit risk \\
May & Moderate credit risk & Substantial credit risk \\
April & Moderate credit risk & Substantial credit risk \\
March & Moderate credit risk & Substantial credit risk \\
February & Moderate credit risk & Substantial credit risk \\
January & Moderate credit risk & Substantial credit risk \\
2007 December & Moderate credit risk & Substantial credit risk \\
November & Moderate credit risk & Substantial credit risk \\
October & Moderate credit risk & Substantial credit risk \\
September & Moderate credit risk & Substantial credit risk \\
August & Moderate credit risk & Moderate credit risk \\
July & Moderate credit risk & Moderate credit risk \\
June & Moderate credit risk & Moderate credit risk \\
May & Moderate credit risk & Moderate credit risk \\
April & Moderate credit risk & Moderate credit risk \\
March & Moderate credit risk & Moderate credit risk \\
February & Moderate credit risk & Moderate credit risk \\
January & Moderate credit risk & Moderate credit risk \\
December & Moderate credit risk & Moderate credit risk \\
\hline & Moderate credit risk & Moderate credit risk \\
\hline
\end{tabular}

Besides potentially lulling investors into a false sense of security, stable ratings and descriptors can also have capital implications for Banks. The Basel standardized model (Bank for International Settlements, 2004, 2011) requires $8 \%$ of risk weighted assets to be held as capital, with corporate weightings depending on external ratings. Thus if the rating is inadequate, the capital is also inadequate. Conversely, a bank could be holding excess capital in upturns. Allen, Kramadibrata, Powell and Singh (2011), using a US portfolio consisting of a mixture of investment and speculative grade companies, showed that, under the Basel Accord standardised model, capital allocation was only required to increase by a fraction of one percentage point during the GFC based on credit ratings, against a backdrop of more than $300 \%$ increase in impaired assets and default probabilities. Banks, globally, during the GFC were beset by capital shortages with many global banks simply running out of capital or requiring government bailouts and recapitalisation. We have already shown how static ratings can be very different to our ratings. In our Renault example, a Baa rating under Basel requires the bank to hold 4\% capital (50\% of $8 \%$ ), which based on Moody's ratings would have stayed the same throughout the period. In contrast, our model would have increased this to $8 \%(100 \%$ of $8 \%)$ when it reached a $\mathrm{B}$ rating and to $12 \%(150 \%$ of $8 \%)$ at the Caa level. Again this is far more in line with the changing fortunes of Renault than a static capital allocation. 


\section{CONCLUSION}

The research can address a major gap in existing knowledge. The prior deliberation has shown that while existing ratings models can be good at measuring risk at the time of the rating, they fail to respond to changing circumstances, thus providing market participants with a false perception of the underlying risk, and banks with inadequate capital. Our dynamic model on the other hand, does fluctuate with changing economic circumstances. Such a dynamic model can advance knowledge on credit ratings and capital adequacy in volatile economic circumstances. It can improve understanding of the underlying risk for bond investors and for banks regarding the credit risk of borrowers and the capital needed to counter this risk.

As mentioned in our introduction, this paper is not meant to be a comprehensive analysis, but an exploratory paper which outlines a potential new framework for dynamic credit ratings. This lays the foundation for moving to an extensive analysis across industries and economic cycles, which will improve the knowledge of all market participants (banks, regulators and investors) as to how risks differ across industries and cycles. This can help investors to make better decisions and banks to make better lending and capital adequacy decisions.

\section{ACKNOWLEDGEMENTS}

We thank the Australian Research Council and Edith Cowan University for funding support.

\section{REFERENCES}

Allen, D. E., Kramadibrata, A. R., Powell, R. J., \& Singh, A. K. (2011). Are Credit Models a Good Indicator of Capital Adequacy? Paper presented at the MODSIM2011 Conference, Perth.

Allen, D. E., Kramadibrata, A. R., Powell, R. J., \& Singh, A. K. (2013). Default Risk in the European Automotive Industry. International Review of Business Research Papers, 9(1), 22-37.

Allen, D. E., \& Powell, R. J. (2010). Customers and Markets: Both Are Essential to Measuring Credit Risk in Australia. Australasian Accounting, Business \& Finance Journal 5(1), 57-75.

Auvray, T., \& Brossard, O. (2012). Too Dispersed to Monitor? Ownership Dispersion, Monitoring, and the Prediction of Bank Distress. Journal of Money, Credit and Banking, 44, 685-714.

Bank for International Settlements. (2004). Basel II: International Convergence of Capital Measurement and Capital Standards: a Revised Framework. Retrieved 11 June, 2009, from http://www.bis.org/publ/bcbs107.htm

Bank for International Settlements. (2011). Basel III: A Global Regulatory Framework for More Resilient Banks and Banking Systems - Revised Version June 2011. Retrieved 2 February 2013, from http://www.bis.org

Bharath, S. T., \& Shumway, T. (2008). Forecasting Default with the Merton Distance-to-Default Model. The Review of Financial Studies, 21(3), 1339-1369.

Crosbie, P., \& Bohn, J. (2003). Modelling Default Risk. Retrieved 16 August 2009, from http://www.moodyskmv.com/research/files/wp/ModelingDefaultRisk.pdf

Engel, R. F. (2011). Long Term Skewness and Systemic Risk. Journal of Financial Econometrics, 9( 3), 437468.

Keys, B., Mukherjee, T., Seru, A., \& Vig, V. (2010). Did securitization Lead to lax Screening? Evidence From Subprime Loans. Quarterly Journal of Economics, 125,(1), 307-362.

Merton, R. (1974). On the pricing of corporate debt: The risk structure of interest rates. Journal of Finance, 29, p.p. 449-470.

Moody's Investor Services. (2010). Corporate Default and Recovery Rates Retrieved 1 February, 2013, from http://efinance.org.cn/cn/FEben/Corporate $\% 20$ Default $\% 20$ and $\% 20$ Recovery $\% 20$ Rates, 1920 2010.pdf

Moody's Investor Services. (2013a). Moodys Rating Symbols and Definitions. Retrieved 5 July, 2013, from www.moody's.com

Moody's Investor Services. (2013b). Ratings Policy and Approach. Retrieved 1 February, 2013, from http://www.moodys.com

Reserve Bank of Australia. (2009a). Financial Stability Review, September.

Reserve Bank of Australia. (2009b). Financial Stability Review, March. 